\title{
Management of the Malignant Polyp
}

\author{
Marcela Ramirez, M.D., ${ }^{1}$ Steven Schierling, M.D., ${ }^{1}$ \\ Harry T. Papaconstantinou, M.D., ${ }^{1}$ and J. Scott Thomas, M.D. ${ }^{1}$
}

In the United States, the prevalence of adenomatous polyps found during colonoscopic evaluation ranges from 25 to $41 \%$, and of these, 2 to $5 \%$ contain invasive malignancy. The management of the malignant polyp continues to be challenging. Endoscopic resection by polypectomy has been shown to be sufficient for management of certain polyps containing cancer; however, it is important to keep in mind that polypectomy does not remove the lymph node drainage basin and may be an inadequate resection for some adenocarcinoma containing polyps that have specific histologic features. Depth of invasion has been shown to correlate with the risk of lymph node metastasis. Other unfavorable histologic features include lymphovascular invasion, poor differentiation, inability to assess margin (piecemeal resection), and positive resection margin $(<2 \mathrm{~mm})$; these are important factors to consider in management. For these patients formal oncologic surgical resection is indicated. Traditional open or laparoscopic procedures are routinely used for colectomy in these patients. Following polypectomy or segmental colectomy, surveillance of these patients is critical, and can lead to excellent long-term outcomes.

KEYWORDS: Malignant polyp, adenocarcinoma, adenomatous polyp, endoscopic polypectomy, segmental colectomy, Haggitt level

\begin{abstract}
Objectives: Upon completion of this article, the reader should be able to recommend appropriate management strategies for the malignant polyp of the colon or rectum based upon histopathologic analysis of the specimen.
\end{abstract}

In the United States, colon and rectal cancer continue to be a major health problem with $\sim 150,000$ new cases diagnosed this year and nearly 50,000 deaths related to the disease. ${ }^{1}$ Screening colonoscopies continue to be performed in the hope of removing benign polyps prior to malignant degeneration through the wellrecognized adenoma-carcinoma sequence. Polyps are simply defined as a macroscopic protrusion of the colonic mucosa into the bowel lumen. ${ }^{2}$ This is usually from abnormal growth of the mucosa regardless of its histologic nature. Polyps include adenomatous, inflammatory, hamartomatous, and hyperplastic lesions. Colonoscopic

${ }^{1}$ Department of Surgery, Division of Surgical Oncology, Section of Colon and Rectal Surgery, The Texas A\&M University Health Science Center, Scott \& White Memorial Hospital, Temple, Texas.

Address for correspondence and reprint requests: J. Scott Thomas, M.D., Department of Surgery, Division of Surgical Oncology, Section of Colon and Rectal Surgery, The Texas A\&M University Health Science Center, Scott \& White Memorial Hospital, 2401 South 31st studies in the United States have shown prevalence rates of adenomatous polyps to be in the range of 25 to $41 \%{ }^{3-7}$ Of these adenomas which are endoscopically resected, 2 to $5 \%$ contain invasive malignancy. ${ }^{2}$ For the purposes of this review, the focus will be on adenomatous polyps and the management of the malignant polyp.

\section{ADENOMATOUS POLYPS}

Adenomatous polyps are by definition benign, but the subsequent development of malignancy makes them particularly important to the endoscopist and surgeon.

St., Temple, TX 76508 (e-mail: jsthomas@swmail.sw.org).

Polyps and Polyposis Coli; Guest Editor, Janice F. Rafferty, M.D.

Clin Colon Rectal Surg 2008;21:286-290. Copyright (C) 2008 by

Thieme Medical Publishers, Inc., 333 Seventh Avenue, New York, NY 10001, USA. Tel: +1(212) 584-4662.

DOI 10.1055/s-0028-1089944. ISSN 1531-0043. 
These polyps consist of epithelial growths of abnormal glands accompanied by a varying amount of villous component (tubular, tubulovillous, and villous adenomas). Polyps can be classified by their macroscopic structural configuration, such as sessile (broad base) or pedunculated, and by their histologic appearance including villous component and degree of dysplasia. Although these polyps are benign, varying degrees of dysplasia may be seen within them. Severe dysplasia, high-grade dysplasia, and carcinoma in situ are all synonymous and denote the high risk of malignant transformation over time. Other factors affecting risk of malignancy include polyp size, extent of villous component, and patient age. ${ }^{8}$ In a study from St. Mark's Hospital, the degree of dysplasia was clearly associated with risk of the polyp harboring malignancy. The investigators showed that only $5.7 \%$ of polyps with mild dysplasia harbored malignancy, whereas nearly $35 \%$ of polyps with severe dysplasia had a focus of adenocarcinoma. Furthermore, the size of the polyp is associated with risk of malignancy, with studies showing the presence of cancer in $1.3 \%$ of adenomas $<1 \mathrm{~cm}$ in size, $9.5 \%$ of adenomas between 1 and $2 \mathrm{~cm}$, and $46 \%$ of adenomas $\geq 2 \mathrm{~cm} .{ }^{9}$ Finally, the risk of finding a cancer in an adenomatous polyp increases with age. Colonoscopy studies in average-risk individuals have demonstrated adenoma rates ranging from 21 to $28 \%$ in those aged 50 to 59,41 to $45 \%$ in those aged 60 to 69 , and 53 to $58 \%$ in those aged 70 or older. ${ }^{5,6}$

The term "malignant polyp" refers to a macroscopically benign appearing adenoma in which the invasive carcinoma is detected after histologic examination of the resected specimen. The muscularis mucosa must be breached to be defined as malignant. Prior studies have suggested that $\sim 5 \%$ of endoscopically resected adenomas will contain malignancy. ${ }^{10}$ The management of these malignant polyps varies based on histologic features, surgical risk of the patient, depth of invasion into the bowel wall, and level of involvement of the polyp.

\section{MANAGEMENT}

Polypectomy is usually performed during colonoscopy using snare polypectomy techniques. High-quality polypectomy is the complete excision of the polyp, which should include the entire stalk to its base. The submucosa of the bowel wall should be included to allow optimal histologic evaluation of the margins.

\section{When Is Endoscopic Resection Adequate?}

The level of invasion into the polyp is a critical factor and dictates whether the endoscopic management of a malignant polyp is adequate. This depth of invasion has been shown to correlate with the risk of lymph node metastasis. Haggitt et $\mathrm{al}^{11}$ described a classification system for pedunculated polyps with levels of invasion ranging from 0 to 4 (Fig. 1). Level 0 indicates carcinoma in situ or intramucosal carcinoma. These lesions are not invasive, and therefore behave as benign adenomas due to an absence of lymphatics in the mucosal layer. Level 1 lesions have adenocarcinoma invading through the muscularis mucosa into the submucosa, and are strictly limited to the head of the polyp. Carcinomas invading to the neck of the polyp are considered level 2 lesions. Invasion of the carcinoma into the stalk of the polyp is level 3 invasion. Level 4 lesions signify invasion of the adenocarcinoma into the bowel wall below the polyp stalk, and is limited to the submucosa. Sessile polyps do not contain stalks, and are considered to be equivalent to a level 4 pedunculated polyp with respect to their incidence of lymph node metastasis. Due to a lack of characterization of sessile lesions in the Haggitt classification and the recognition that the risk of lymph node metastasis in each level 4 lesion is not the same, Kudo ${ }^{12}$ classified these lesions into three levels (Fig. 2). Submucosal invasion was classified into thirds with $\mathrm{Sm}_{1}$ lesions exhibiting invasion into the upper third of the submucosa, $\mathrm{Sm}_{2}$ invasion into the middle third of the submucosa, and $\mathrm{Sm}_{3}$ invasion into the lower third of the submucosa.

The adequacy of endoscopic resection is dependent on the risk of nodal metastasis, as endoscopic resection does not remove or sample the lymph node drainage basin. Many studies have shown that the incidence of nodal metastasis is $<1 \%$ for polyps completely removed endoscopically with a Haggitt level 1, 2, or 3 level of invasion. ${ }^{11,13}$ Cranley and colleagues suggest a $0.3 \%$ incidence of nodal involvement in pedunculated polyps with favorable criteria. ${ }^{14}$ For Haggitt level 4 lesions with favorable histology or sessile lesions with $\mathrm{Sm}_{1}$ or $\mathrm{Sm}_{2}$ depth without additional unfavorable histologic features, it is felt that these lesions are low risk and can be favorably managed with endoscopic polypectomy alone provided margins are $>2 \mathrm{~mm} .{ }^{13}$ Pedunculated polyps with Haggitt level 4 lesions exhibiting unfavorable histology, sessile lesions with $\mathrm{Sm}_{1}$ or $\mathrm{Sm}_{2}$ depth and poor histologic features, and sessile lesions with $\mathrm{Sm}_{3}$ depth have a much higher incidence of lymph node metastasis and ranges from 12 to $25 \%$, indicating that a formal oncologic resection is necessary for successful treatment and optimal outcome. ${ }^{15-17}$

Unfavorable features that define poor histology include lymphovascular invasion (LVI), poor differentiation, and positive resection margin $(<2 \mathrm{~mm}) .{ }^{18} \mathrm{In}$ a pooled data analysis, LVI has been shown to be present in as many as $56 \%$ of specimens from individual series with an overall average of $17 \% .{ }^{19}$ The presence of LVI is more frequent in sessile lesions compared with pedunculated lesions, and the incidence of lymph node metastasis was significantly more common when LVI was identified (35\% versus 7\%); however, distant metastatic disease and mortality showed no statistically significant 


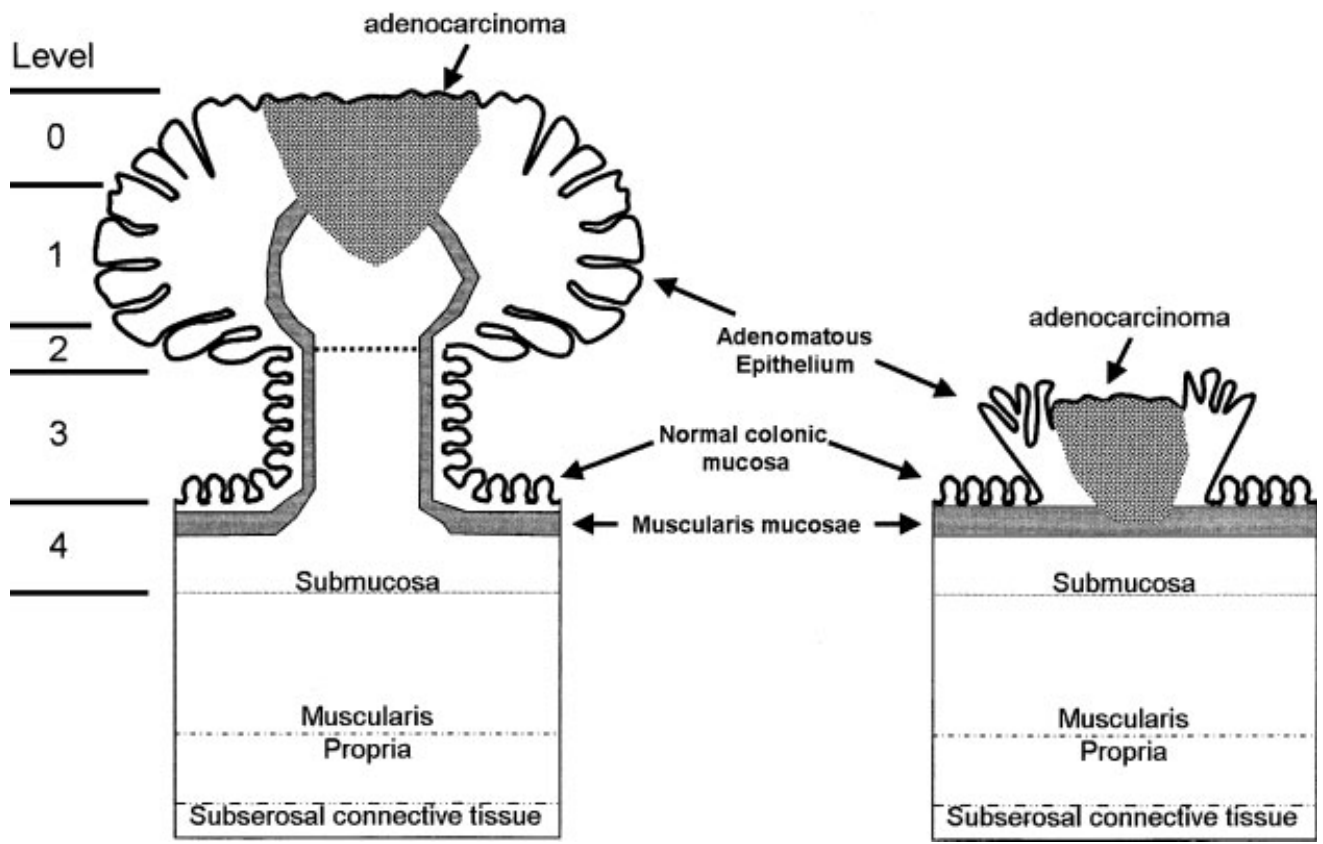

Figure 1 Anatomic landmarks of pedunculated and sessile malignant polyps with respect to Haggitt level. Adapted from Haggitt et al. $^{11}$

difference between the groups. Poorly differentiated features were identified in $7 \%$ of specimens, ${ }^{19}$ and were associated with a statistically significant increase in positive lymph node metastasis (23\% versus $7 \%$ ), distant metastasis (9\% versus $2 \%$ ) and cancer-related death (14\% versus $1.8 \%)$. Finally, a positive margin of resection led to a significant increase in local recurrence of disease (30\% versus 2.8\%), distant metastasis (9\% versus $1 \%)$, and cancer related death (85\% versus $1.4 \%)$. Interestingly, the incidence of lymph node metastasis did not reach statistical significance when considering margin of resection. ${ }^{19}$

Removal of a polyp via piecemeal technique will complicate the histologic interpretation of the margin, and should be avoided. Other techniques such as endoscopic mucosal resection or treatment of the polyp bed with argon beam/electrocautery, though possibly effective, may leave some doubt as to the true status of the margin of resection, and has not been studied. ${ }^{20-22}$

\section{SURGICAL RESECTION}

When considering the above discussion and the fact that $20 \%$ of polyps that are colonoscopically unresectable will harbor invasive malignancy after histologic evaluation, formal oncologic surgical resection is recommended. Oncologic segmental resection is indicated for the following polyps and histologic features ${ }^{23}$ :

- Haggitt level 4 lesions with distal third submucosa invasion

- Malignant polyp with margin of resection $<2 \mathrm{~mm}$

- Evidence of vascular or lymphatic invasion
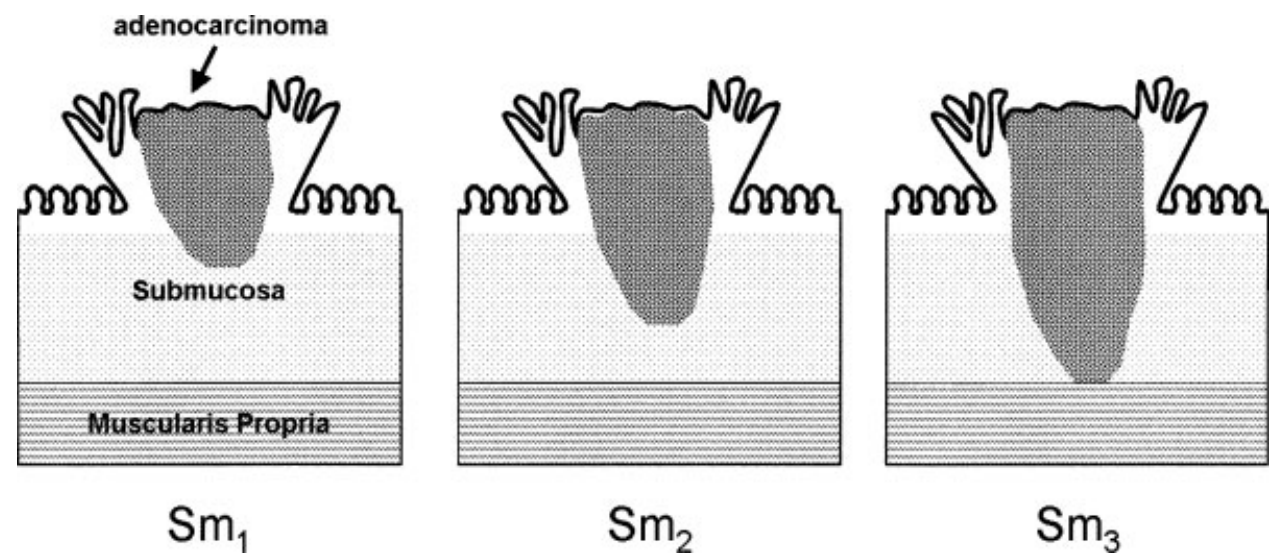

Figure 2 Depth of submucosal invasion in sessile malignant polyps. $\mathrm{Sm}_{1}$, invasion into upper third; $\mathrm{Sm}_{2}$, invasion into middle third; $\mathrm{Sm}_{3}$, invasion into lower third. Adapted from Kudo. ${ }^{12}$ 
- Incomplete resection or inability to assess margin (piecemeal technique)

- Sessile lesion with Sm3 invasion

This can be done in the traditional open approach or via laparoscopic techniques. The laparoscopic approach has potential benefits of less postoperative pain, faster return of postoperative bowel function, improved cosmesis, earlier return to work, less operative blood loss, shorter hospitalization, reduced overall costs, fewer postoperative bowel obstructions, and a lower incidence of ventral hernia when compared with the open approach. ${ }^{24-26}$ These benefits make the laparoscopic approach a favorable option for these patients, and may be beneficial in elderly patients or patients with significant comorbid medical conditions with a colonoscopically unresectable lesion. ${ }^{27}$

Recent reports show enthusiasm for laparoscopicassisted colonoscopic polypectomy, which is a combined procedure that involves the laparoscopic mobilization of the colon to facilitate traditional endoscopic polypectomy techniques. ${ }^{28-31}$ The addition of laparoscopy allows for direct observation of the polypectomy site; if colonic perforation or thermal injury is noted, the injury can be repaired easily and immediately during the procedure. The use of frozen section allows for the determination of malignant invasion after which a segmental resection can then be performed if pathology indicates. This may allow for management of larger lesions previously felt to be colonoscopically unresectable or lesions that are in anatomically unfavorable locations. The procedure provides a recovery time that approximates colonoscopy alone and the morbidity of resection is avoided completely. Conversely, insufflation of the colon for colonoscopy during laparoscopy decreases the usable peritoneal space for pneumoperitoneum making the procedure more technically challenging.

\section{RECTAL LESIONS}

A comment must be made regarding management of rectal lesions, specifically lesions of the distal third as they have been shown to have a higher incidence of lymph node metastasis compared with proximal and middle rectal lesions that behave similarly to the colon. ${ }^{15}$ With a distal third rectal lesion, oncologic resection is recommended for all sessile lesions or Haggitt level 4 lesions with penetration into the distal third of the submucosa. An alternative approach of transanal full thickness excision or transanal endoscopic microsurgery (TEMS) plus chemoradiation can also be considered.

\section{SURVEILLANCE}

Close endoscopic follow-up is required to detect local recurrence in the setting of an endoscopically managed malignant polyp. Surveillance endoscopy sufficient to reach the polypectomy site $\sim 2$ to 3 months after polypectomy and then twice yearly thereafter for the first 2 years is felt to be a reasonable approach. A complete surveillance colonoscopy should be performed within 3 years of the initial polypectomy and then every 3 years thereafter pending any additional finding. ${ }^{23}$

For the patient who has received formal, oncologic resection, they should receive a postprocedure baseline colonoscopy at 1 year and then after 3 years. Further colonoscopic surveillance is performed every 5 years thereafter unless findings dictate more frequent examinations.

\section{CONCLUSION}

Adenomatous polyps harboring a focus of adenocarcinoma are a complex problem. Management is dependent on risk of lymph node metastasis, and therefore, risk of recurrence and spread. Endoscopic polypectomy is sufficient for these malignant polyps provided they exhibit favorable histology, limited depth of invasion, and a minimum of $2 \mathrm{~mm}$ margin. In contrast, poor histology or more extensive invasion warrants formal oncologic bowel resection, assuming that the patient is an acceptable operative candidate. ${ }^{32,33}$ Regular endoscopic surveillance is important to identify presence of local recurrence or identify new polyps or cancers.

\section{REFERENCES}

1. National Cancer Institute. Types of colon and rectal cancer. Available at: http://www.cancer.gov/cancertopics/types/colonand -rectal. Accessed September 16, 2008

2. Markowitz AJ, Winawer SJ. Management of colorectal polyps. CA Cancer J Clin 1997;47(2):93-112

3. Winawer SJ, Zauber AG, O'Brien MD, et al. The National Polyp Study: design, methods, and characteristics of patients with newly diagnosed polyps. Cancer 1992;70:1236-1245

4. Rex DK, Lehman GA, Hawes RH, Ulbright TM, Smith JJ. Screening colonoscopy in asymptomatic average risk persons with negative fecal occult blood tests. Gastroenterology 1991; 100:64-67

5. Lieberman DA, Smith FW. Screening for colon malignancy with colonoscopy. Am J Gastroenterol 1991;86:946951

6. DiSario JA, Foutch PG, Mai HD, et al. Prevalence and malignant potential of colorectal polyps in asymptomatic, average-risk men. Am J Gastroenterol 1991;86:941-945

7. Rogge JD, Elmore MF, Mahoney SJ, et al. Low-cost, officebased, screening colonoscopy. Am J Gastroenterol 1994;89: $1775-1780$

8. O’Brien MJ, Winawer SJ, Zauber AG, et al. The National Polyp Study: Patient and polyp characteristics associated with high-grade dysplasia in colorectal adenomas. Gastroenterology 1990;98:371-379

9. Muto T, Bussey HJR, Morson BC. The evolution of cancer of the colon and rectum. Cancer 1975;36:2251-2270 
10. Wolff WI, Shinya H. Definitive treatment of "malignant" polyps of the colon. Ann Surg 1975;182:516-525

11. Haggitt RC, Glotzbach RE, Soffer EE, Wruble LD. Prognostic factors in colorectal carcinomas arising in adenomas: implications for lesions removed by endoscopic polypectomy. Gastroenterology 1985;89 (2):328-336

12. Kudo S. Endoscopic mucosal resection of flat and depressed types of early colorectal cancer. Endoscopy 1993;25 (7):455461 Review

13. Nivatvongs S. Surgical management of malignant colorectal polyps. Surg Clin North Am 2002;82 (5):959-966; Review

14. Cranley JP, Petras RE, Carey WE, et al. When is endoscopic polypectomy adequate therapy for colonic polyps containing invasive carcinoma? Gastroenterology 1986;91:419-427

15. Nascimbeni R, Burgar LJ, Nivatvongs S, Larson DR. Risk of lymph node metastasis in T1 carcinoma of the colon and rectum. Dis Colon Rectum 2002;45:200-206

16. Cooper HS, Deppisch LM, Gourley WK, et al. Endoscopically removed malignant colorectal polyps: clinicopathologic correlations. Gastroenterology 1995;108:1657-1665

17. Coverlizza S, Risio M, Ferrari A, et al. Colorectal adenomas containing invasive carcinoma. Pathologic assessment of lymph node metastatic potential. Cancer 1989;64:19371947

18. Muto T, Sawada T, Sugihara K. Treatment of carcinoma in adenomas. World J Surg 1991;15:35-40

19. Hassan C, Zullo A, Risio M, Rossini FP, Morini S. Histologic risk factors and clinical outcome in colorectal malignant polyp: a pooled-data analysis. Dis Colon Rectum 2005;48(8):1588-1596

20. Löhnert MS, Wittmer A, Doniec JM. [Endoscopic removal of large colorectal polyps]. Zentralbl Chir 2004;129(4):291295

21. Zlatanic J, Waye JD, Kim PS, Baiocco PJ, Gleim GW. Large sessile colonic adenomas: use of argon plasma coagulator to supplement piecemeal snare polypectomy. Gastrointest Endosc 1999;49(6):731-735

22. Fukami N, Lee JH. Endoscopic treatment of large sessile and flat colorectal lesions. Curr Opin Gastroenterol 2006;22 (1):54-59; Review
23. Burnstein MJ, Hicks TC. Polyps. In: Wolff BG, Fleshman JW, Beck DE, Pemberton JH, Wexner SD, eds. The ASCRS Textbook of Colon and Rectal Surgery. New York: Springer; 2007:366-368

24. Delaney CP, Kiran RP, Senagore AJ, Brady K, Fazio VW. Case-matched comparison of clinical and financial outcome after laparoscopic or open colorectal surgery. Ann Surg 2003; 238(1):67-72

25. Duepree HJ, Senagore AJ, Delaney CP, Fazio VW. Does means of access affect the incidence of small bowel obstruction and ventral hernia after bowel resection? Laparoscopy versus laparotomy. J Am Coll Surg 2003;197(2):177-181

26. Kiran RP, Delaney CP, Senagore AJ, Millward BL, Fazio VW. Operative blood loss and use of blood products after laparoscopic and conventional open colorectal operations. Arch Surg 2004;139(1):39-42

27. Lo SH, Law WL. Laparoscopic colorectal resection for polyps not suitable for colonoscopic removal. Surg Endosc 2005;19(9):1252-1255

28. Franklin ME Jr, Díaz-E JA, Abrego D, Parra-Dávila E, Glass JL. Laparoscopic-assisted colonoscopic polypectomy: the Texas Endosurgery Institute experience. Dis Colon Rectum 2000;43(9):1246-1249

29. Prohm P, Weber J, Bönner C. Laparoscopic-assisted colonoscopic polypectomy. Dis Colon Rectum 2001;44(5):746-748

30. Hensman C, Luck AJ, Hewett PJ. Laparoscopic-assisted colonoscopic polypectomy: technique and preliminary experience. Surg Endosc 1999;13:231-232

31. Smedh K, Skullman S, Kald A, Anderber B, Nystrom P. Laparoscopic bowel mobilization combined with intraoperative colonoscopic polypectomy in patients with an inaccessible polyp of the colon. Surg Endosc 1997;11:643-644

32. Seitz U, Bohnacker S, Seewald S, et al. Is endoscopic polypectomy an adequate therapy for malignant colorectal adenomas? Presentation of 114 patients and review of the literature. Dis Colon Rectum 2004;47(11):1789-1796; discussion 1796-1797; Review

33. Williams CB, Saunders BP, Talbot IC. Endoscopic management of polypoid early colon cancer. World J Surg 2000;24 (9):1047-1051; Review 